\title{
The role of manganese dioxide in the natural formation of organochlorines
}

\section{Supporting Information}

Warren M. Kadoya ${ }^{1}$, Camila L. Madeira ${ }^{1}$, Christiane Hoppe-Jones ${ }^{1}$, Tom Solsten ${ }^{1}$,

Shane A. Snyder ${ }^{2}$, Robert A. Root ${ }^{3}$, Reyes Sierra-Alvarez ${ }^{1}$, Jon Chorover ${ }^{3}$, and Jim A. Field ${ }^{1, *}$

${ }^{1}$ Department of Chemical and Environmental Engineering, University of Arizona, Tucson, AZ

$$
\text { 85721, USA }
$$

${ }^{2}$ Nanyang Environment \& Water Research Institute (NEWRI), Nanyang Technological

$$
\text { University, Singapore 637141, Singapore }
$$

${ }^{3}$ Department of Environmental Science, University of Arizona, Tucson, AZ 85721, USA

*Corresponding author: Jim A. Field, Email: jimfield@email.arizona.edu, Telephone: 1-520-621-0704

Pages: 14

Tables: 2

Figures: 9 
Table S1. Standard reduction potential $\left(\mathrm{E}^{\circ}\right)$ for selected reduction reactions with $\mathrm{Mn}{ }^{1}$.

\begin{tabular}{|c|c|}
\hline Reaction & $\mathbf{E}^{\circ}(\mathbf{V})$ \\
\hline $\mathrm{MnO}_{2}(s)+4 \mathrm{H}^{+}+2 e^{-} \rightleftharpoons \mathrm{Mn}^{2+}+2 \mathrm{H}_{2} \mathrm{O}(l)$ & 1.23 \\
\hline $\mathrm{MnO}_{2}(s)+4 \mathrm{H}^{+}+e^{-} \rightleftharpoons \mathrm{Mn}^{3+}(a q)+2 \mathrm{H}_{2} \mathrm{O}(l)$ & 0.95 \\
\hline $\mathrm{Mn}^{2+}+2 e^{-} \rightleftharpoons \mathrm{Mn}(s)$ & -1.17 \\
\hline $\mathrm{Mn}^{3+}+e^{-} \rightleftharpoons \mathrm{Mn}^{2+}$ & 1.5 \\
\hline
\end{tabular}


Table S2. Characteristics of the chemicals used in the study of $\mathrm{MnO}_{2}$-mediated formation of halogenated guaiacol.

\begin{tabular}{|c|c|c|c|c|c|c|c|c|}
\hline Guaiacol name & $\begin{array}{c}\text { Methoxyphenol } \\
\text { name }\end{array}$ & CAS \# & Company & $\begin{array}{c}\text { Purity } \\
\text { (\%) }\end{array}$ & Description & Structure & $\begin{array}{c}\text { Retention time } \\
\text { (min) }\end{array}$ & $\begin{array}{c}\text { SIM parameter } \\
\text { quantifier } \\
\text { ion/qualifier ion }\end{array}$ \\
\hline 4-Chloroguaiacol & $\begin{array}{l}\text { 4-Chloro-2- } \\
\text { methoxyphenol }\end{array}$ & $16766-30-6$ & $\begin{array}{c}\text { Alfa Aesar } \\
\text { (Haverhill, } \\
\text { MA) }\end{array}$ & 97 & $\begin{array}{c}\text { Dominant } \\
\text { product } \\
\left(\mathrm{MnO}_{2}+\right. \\
\text { guaiacol }+ \\
\left.\mathrm{Cl}^{-}\right)\end{array}$ & $\mathrm{Cl}$ & $\begin{array}{c}\text { GC-QToF } 14.1 \\
\text { GC-MS/MS 5.65 }\end{array}$ & $\mathrm{m} / \mathrm{z} 158 / 143$ \\
\hline 6-Chloroguaiacol & $\begin{array}{l}\text { 2-Chloro-6- } \\
\text { methoxyphenol }\end{array}$ & $72403-03-3$ & $\begin{array}{c}\text { AstaTech } \\
\text { (Bristol, PA) }\end{array}$ & 95 & $\begin{array}{c}\text { Minor } \\
\text { product } \\
\left(\mathrm{MnO}_{2}+\right. \\
\text { guaiacol }+ \\
\left.\mathrm{Cl}^{-}\right)\end{array}$ & & $\begin{array}{c}\text { GC-QToF } 14.6 \\
\text { GC-MS/MS } 6.12\end{array}$ & $\mathrm{~m} / \mathrm{z} 158 / 143$ \\
\hline 5-Chloroguaiacol & $\begin{array}{l}\text { 5-Chloro-2- } \\
\text { methoxyphenol }\end{array}$ & $3743-23-5$ & $\begin{array}{c}\text { AstaTech } \\
\text { (Bristol, PA) }\end{array}$ & 95 & $\begin{array}{l}\text { Internal } \\
\text { standard }\end{array}$ & & $\begin{array}{c}\text { GC-QToF } 14.2 \\
\text { GC-MS/MS } 5.74\end{array}$ & $\mathrm{~m} / \mathrm{z} 158 / 143$ \\
\hline 4-Bromoguaiacol & $\begin{array}{c}\text { 4-Bromo-2- } \\
\text { methoxyphenol }\end{array}$ & $7368-78-7$ & $\begin{array}{c}\text { Alfa Aesar } \\
\text { (Haverhill, } \\
\text { MA) }\end{array}$ & 98 & $\begin{array}{c}\text { Minor } \\
\text { product } \\
\left(\mathrm{MnO}_{2}+\right. \\
\text { guaiacol }+ \\
\left.\mathrm{Br}^{-}\right)\end{array}$ & $\mathrm{Br}$ & $\begin{array}{c}\text { GC-QToF } 15.4 \\
\text { GC-MS/MS } 6.70\end{array}$ & $\mathrm{~m} / \mathrm{z} 202 / 187$ \\
\hline
\end{tabular}




\begin{tabular}{|c|c|c|c|c|c|c|c|c|}
\hline Guaiacol name & $\begin{array}{c}\text { Methoxyphenol } \\
\text { name }\end{array}$ & CAS \# & Company & $\begin{array}{c}\text { Purity } \\
(\%)\end{array}$ & Description & Structure & $\begin{array}{c}\text { Retention time } \\
(\text { min) }\end{array}$ & $\begin{array}{l}\text { SIM parameter } \\
\text { quantifier } \\
\text { ion/qualifier ion }\end{array}$ \\
\hline \multirow[t]{8}{*}{ 6-Bromoguaiacol } & $\begin{array}{c}\text { 2-Bromo-6- } \\
\text { methoxyphenol }\end{array}$ & $28165-49-3$ & $\begin{array}{l}\text { Alfa Aesar } \\
\text { (Haverhill, } \\
\text { MA) }\end{array}$ & $98+$ & $\begin{array}{c}\text { Dominant } \\
\text { product } \\
\left(\mathrm{MnO}_{2}+\right. \\
\text { guaiacol } \\
\text { Br- })\end{array}$ & & $\begin{array}{c}\text { GC-QToF } 15.9 \\
\text { GC-MS/MS } 7.19\end{array}$ & $\mathrm{~m} / \mathrm{z} 202 / 187$ \\
\hline & Sodium chloride & $7647-14-5$ & $\begin{array}{c}\text { Fisher } \\
\text { Chemicals } \\
\text { (Fairlawn, NJ) }\end{array}$ & & & & & \\
\hline & $\begin{array}{l}\text { Sodium } \\
\text { bromide }\end{array}$ & $7647-15-6$ & $\begin{array}{c}\text { Alfa Aesar } \\
\text { (Haverhill, } \\
\text { MA) }\end{array}$ & $99+$ & & & & \\
\hline & Sodium iodide & $7681-82-5$ & $\begin{array}{c}\text { Alfa Aesar } \\
\text { (Haverhill, } \\
\text { MA) }\end{array}$ & 99.5 & & & & \\
\hline & Sodium sulfate & $7757-82-6$ & $\begin{array}{l}\text { Sigma-Aldrich } \\
\text { (St. Louis, } \\
\text { MO) }\end{array}$ & $99.0+$ & & & & \\
\hline & Guaiacol & $90-05-1$ & $\begin{array}{c}\text { Acros } \\
\text { Organics } \\
\text { (Morris Plains, } \\
\text { NJ) }\end{array}$ & $99+$ & & & & \\
\hline & $\begin{array}{l}\text { Acetic acid } \\
\text { (glacial) }\end{array}$ & $64-19-7$ & $\begin{array}{c}\text { Fisher } \\
\text { Chemicals } \\
\text { (Fairlawn, NJ) }\end{array}$ & & & & & \\
\hline & Sulfuric acid & 7664-93-9 & $\begin{array}{l}\text { Sigma-Aldrich } \\
\text { (St. Louis, } \\
\text { MO) }\end{array}$ & $\begin{array}{c}95.0- \\
98.0\end{array}$ & & & & \\
\hline
\end{tabular}




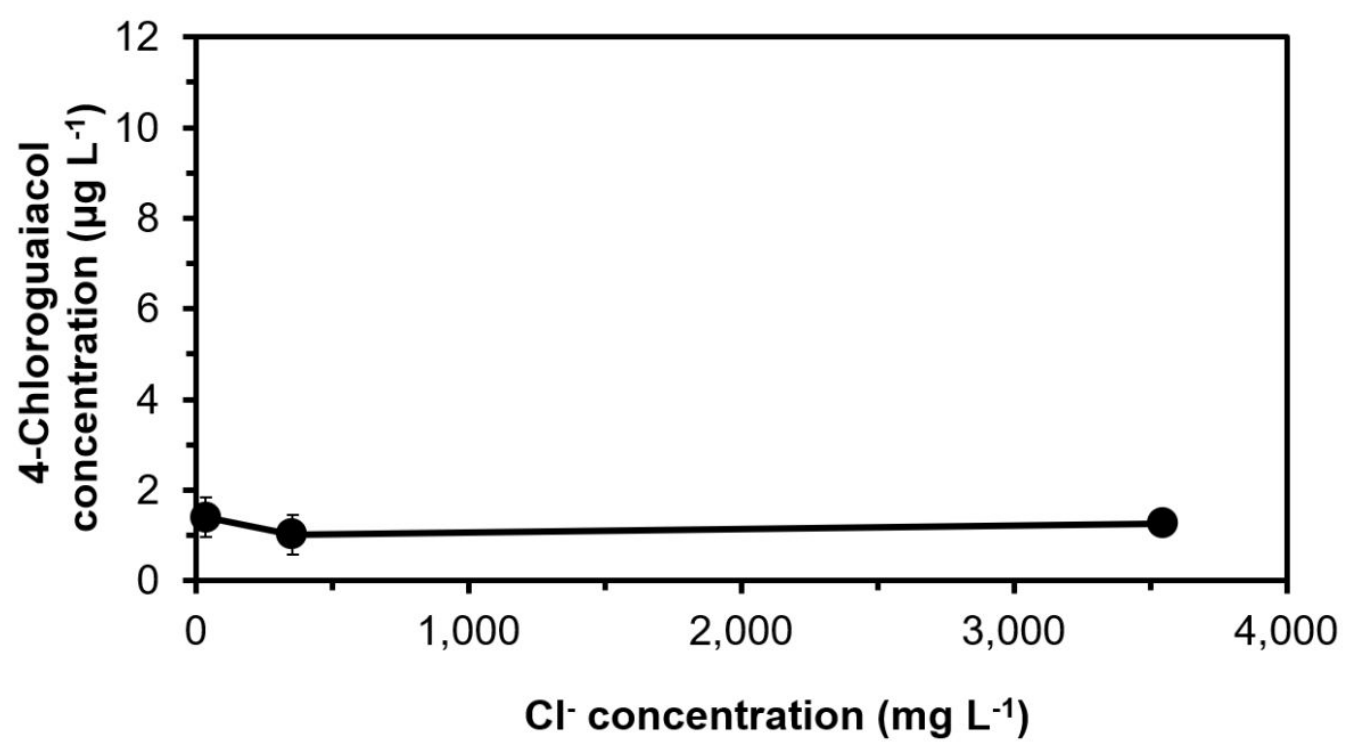

Figure S1. Formation of 4-chloroguaiacol in solutions containing $124 \mathrm{mg} \mathrm{L}^{-1}$ guaiacol and different concentrations of $\mathrm{NaCl}$ after $18 \mathrm{~min}$ of reaction time. The concentrations of 6chloroguaiacol were below the detection limit for all the concentrations of $\mathrm{Cl}^{-}$tested $(35,354$, and 3,545 $\left.\mathrm{mg} \mathrm{L}^{-1}\right)$. The error bars represent the standard deviation $(\mathrm{n}=3)$. 


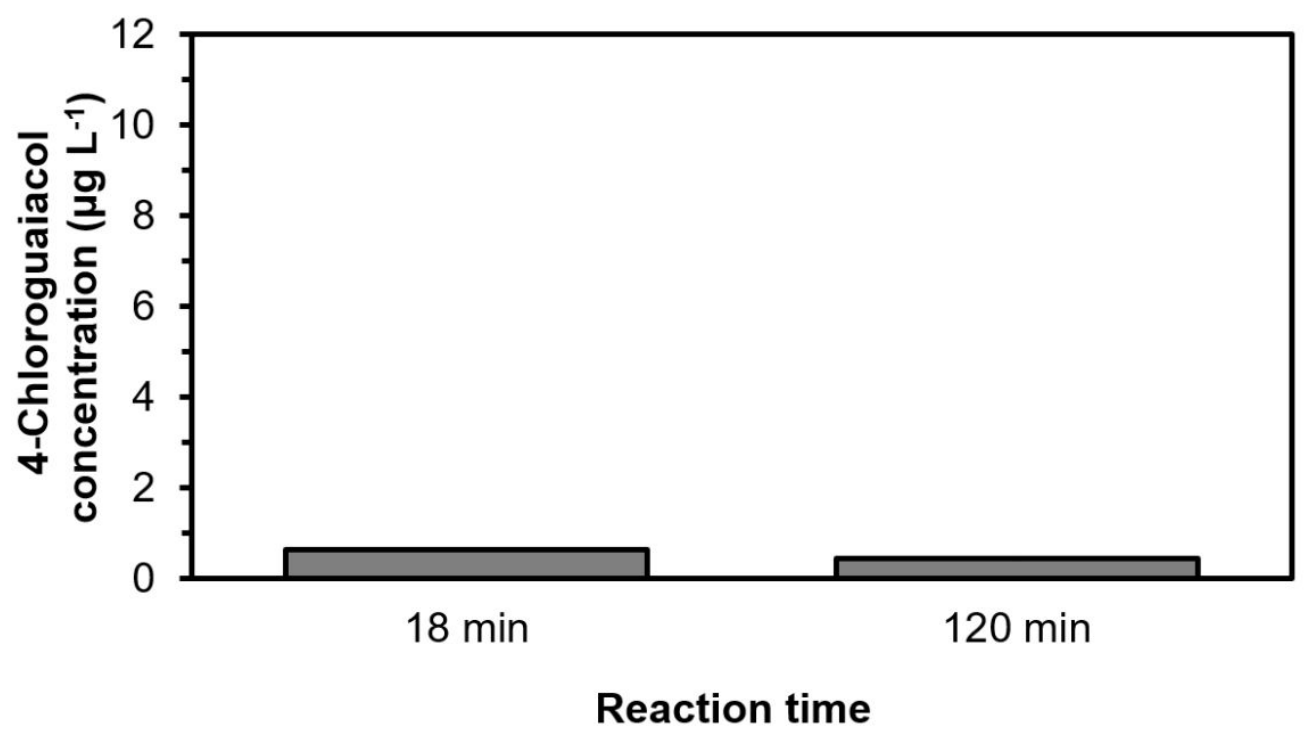

Figure S2. Formation of 4-chloroguaiacol in solutions containing $300 \mathrm{mg} \mathrm{L}^{-1} \mathrm{MnO}_{2}$ and $124 \mathrm{mg}$ $\mathrm{L}^{-1}$ guaiacol after 18 and 120 min of reaction time. The concentrations of 6-chloroguaiacol were below the detection limit. The error bars represent the standard deviation $(n=3)$. 
a)
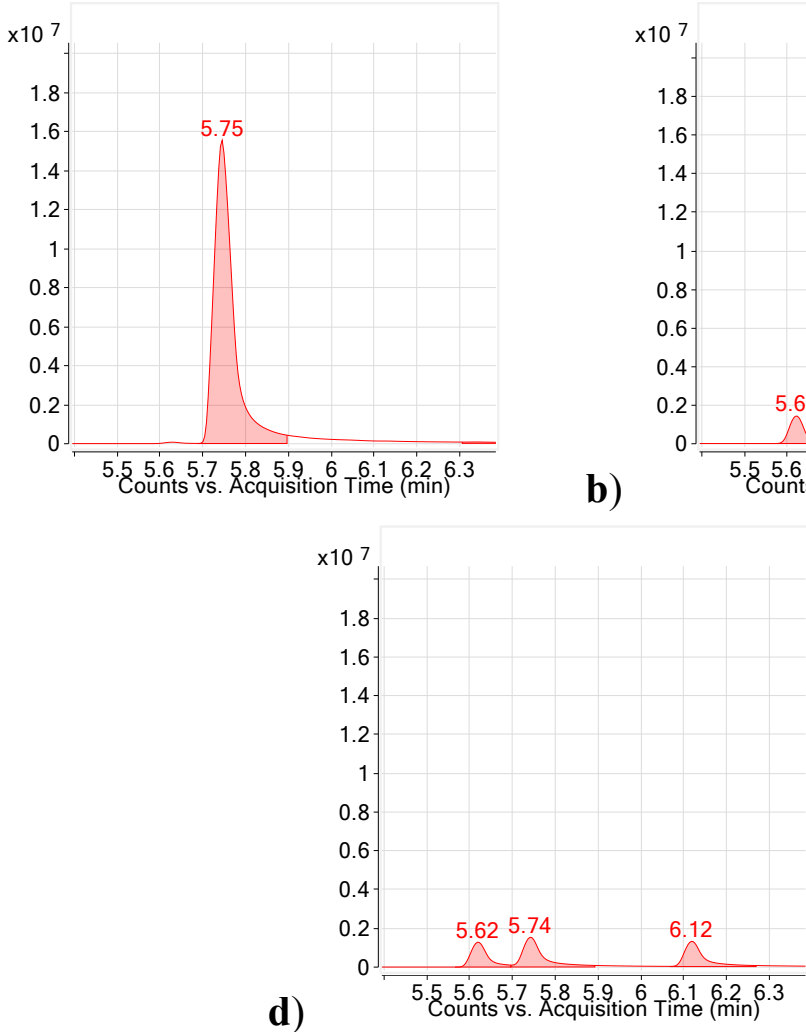
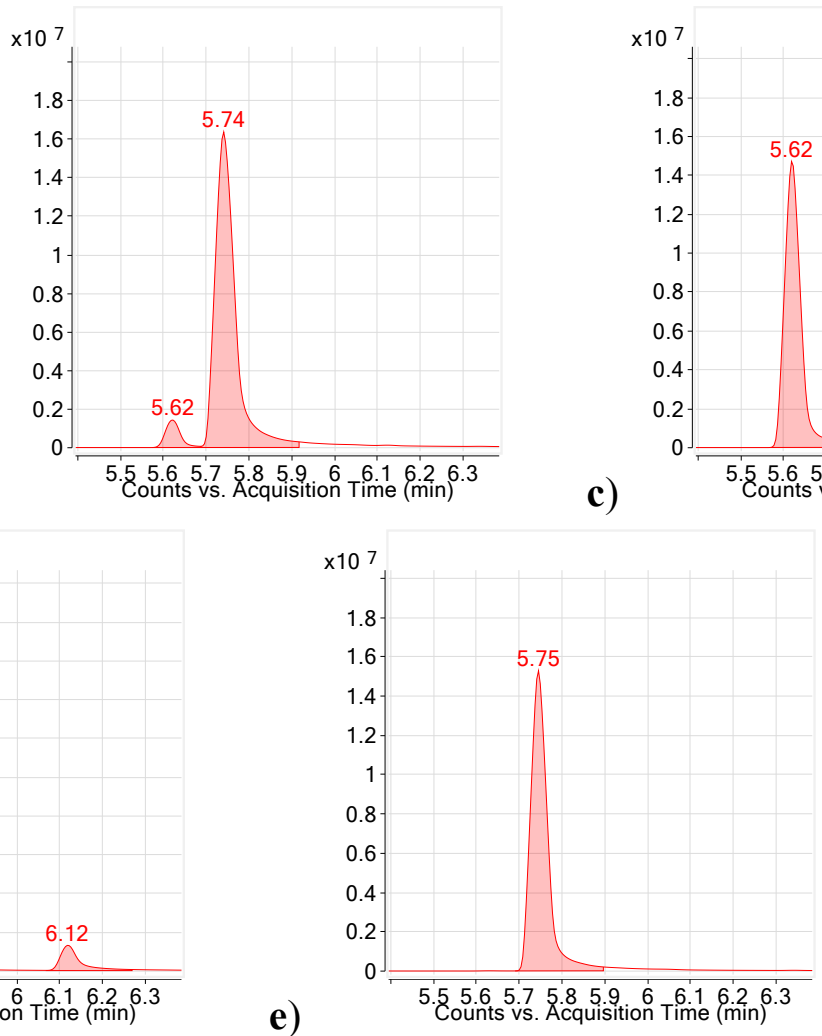

Figure S3. Chromatograms obtained from GC-MS/MS analyses of $18 \mathrm{~min}$ incubations of $124 \mathrm{mg} \mathrm{L}^{-1}$ guaiacol and NaCl with $300 \mathrm{mg} \mathrm{L}-1$ $\mathrm{MnO}_{2}$. Panels (a), (b), and (c) correspond to 35, 354, and 3,545 $\mathrm{mg} \mathrm{L}^{-1} \mathrm{Cl}^{-}$, respectively. The products in order of peak retention time are as follows: $5.6 \mathrm{~min}$ (4-chloroguaiacol) and $6.1 \mathrm{~min}$ (6-chloroguaiacol). The large peak at $5.7 \mathrm{~min}$ is the internal standard, 5chloroguaiacol. Panel (d) corresponds to a $500 \mu \mathrm{g} \mathrm{L}^{-1}$ standard of the two products and internal standard. Panel (e) shows a $\mathrm{MnO}_{2}$-free control. No product peaks were detected in the absence of $\mathrm{MnO}_{2}$. 


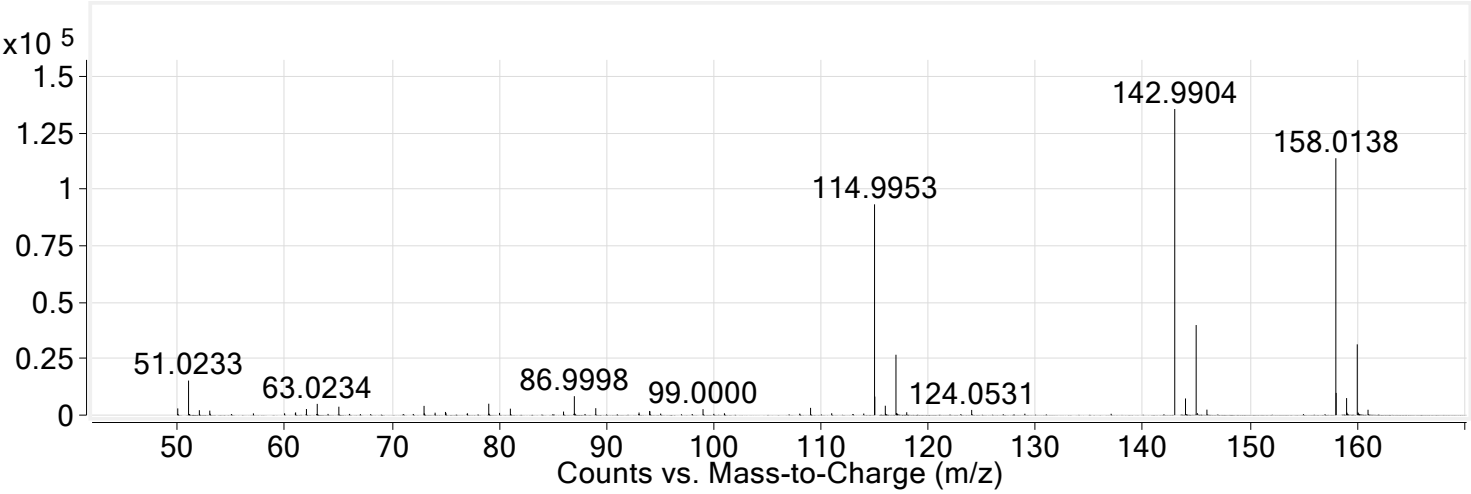

a)

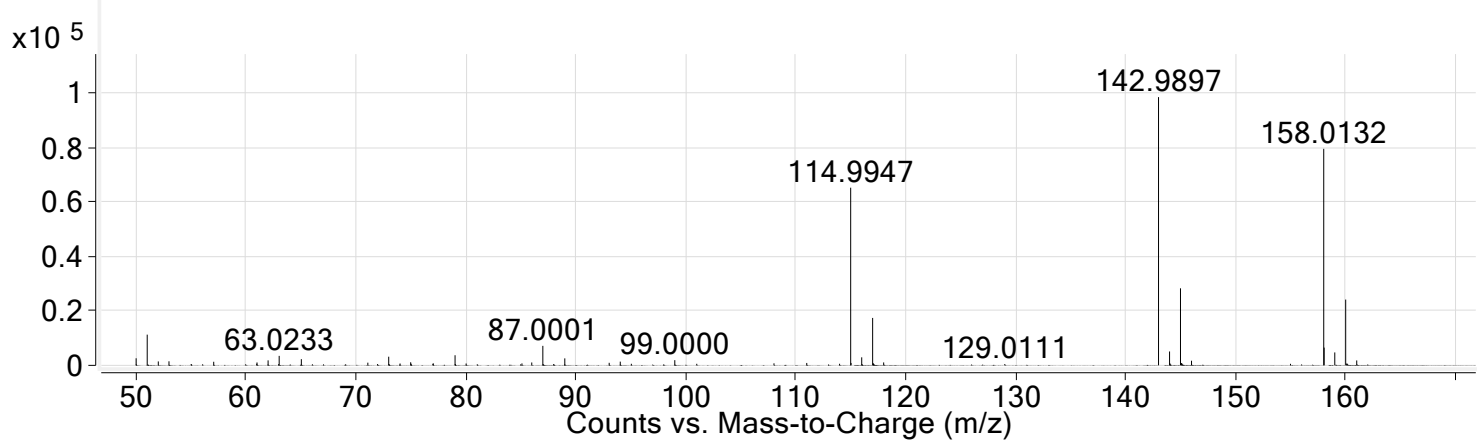

b)

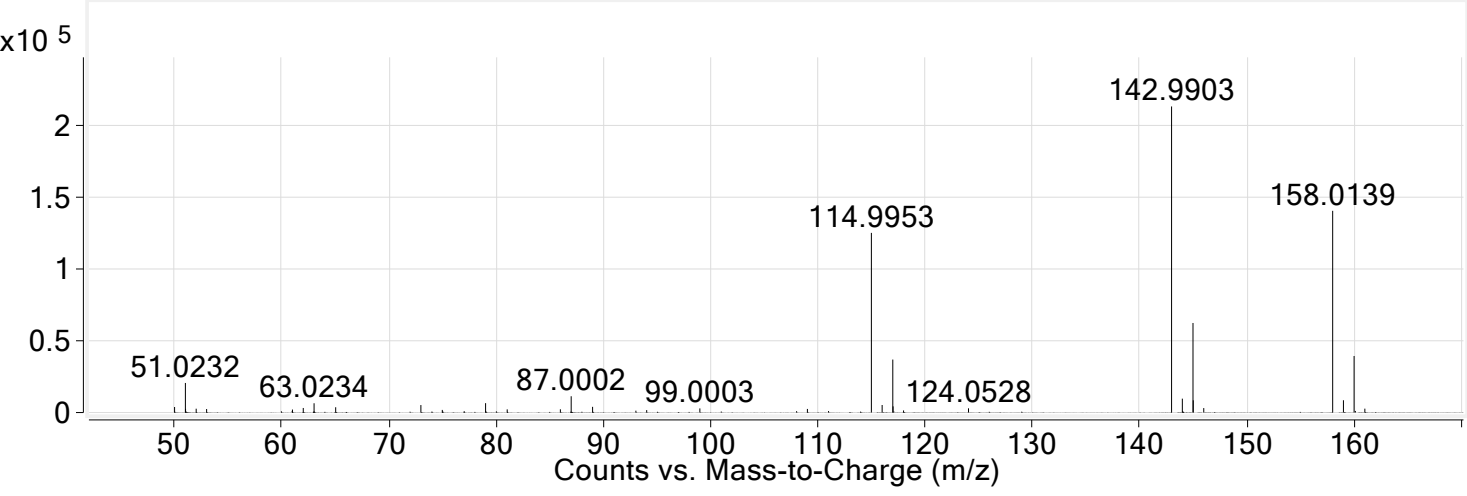

c)

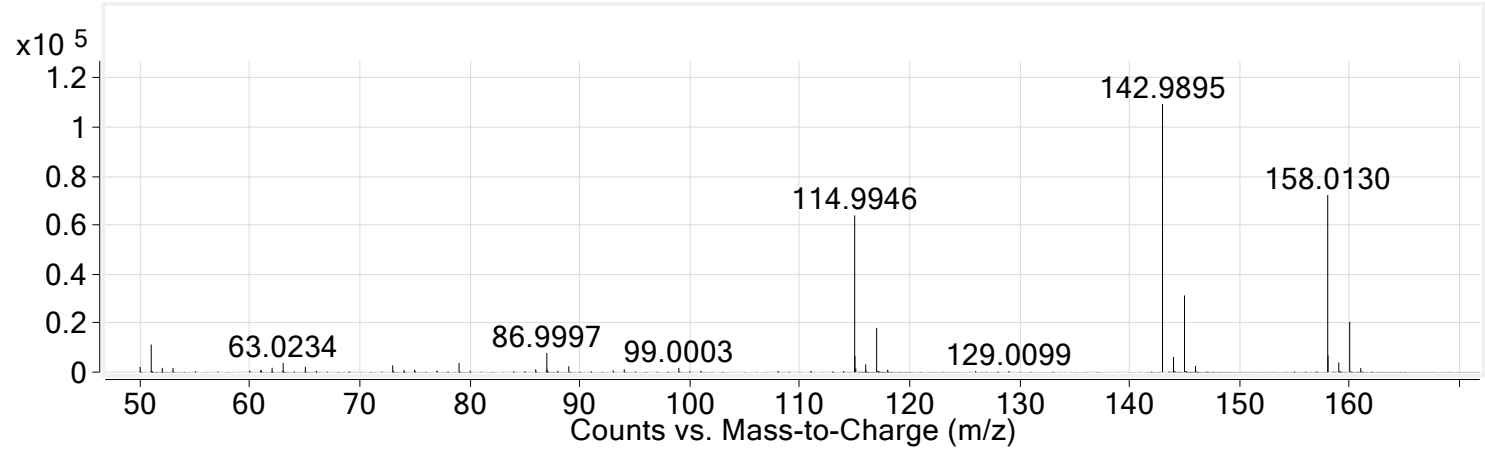

Figure S4. Mass spectra obtained from GC-QToF analyses of an $18 \mathrm{~min}$ incubation of $300 \mathrm{mg} \mathrm{L}^{-}$ ${ }^{1} \mathrm{MnO}_{2}$ with $124 \mathrm{mg} \mathrm{L}^{-1}$ guaiacol and 8,862 $\mathrm{mg} \mathrm{L}^{-1} \mathrm{Cl}^{-}$. Panel (a) is a spectrum of 4-chloroguaiacol at $14.3 \mathrm{~min}$, with mass difference $-5.6 \mathrm{ppm}$ and NIST Match Factor 862; panel (b) is a $1 \mathrm{mg} \mathrm{L}^{-1}$ standard for 4-chloroguaiacol at $14.3 \mathrm{~min}$. Panel (c) is a spectrum of 5-chloroguaiacol at $14.5 \mathrm{~min}$, with mass difference -6.3 ppm and NIST Match Factor 901; panel (d) is a $1 \mathrm{mg} \mathrm{L}^{-1}$ standard for 5chloroguaiacol at $14.5 \mathrm{~min}$. 
a)
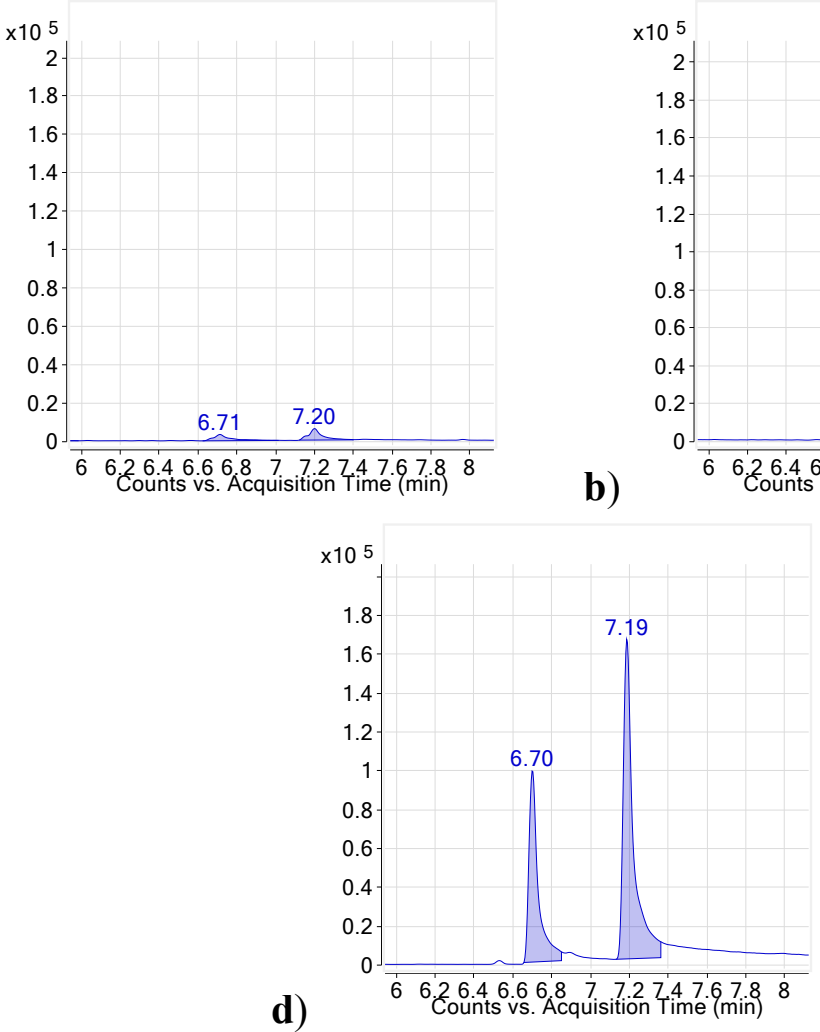

d) c)

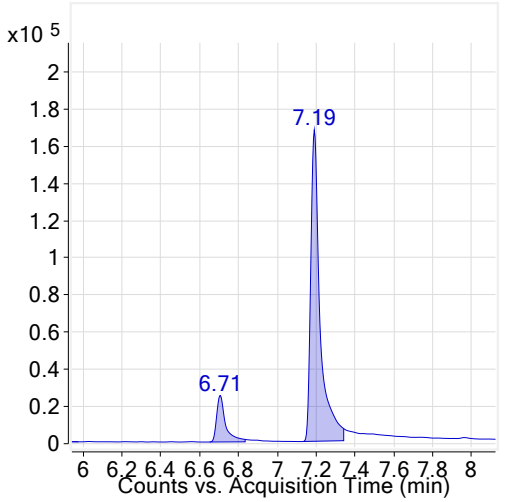

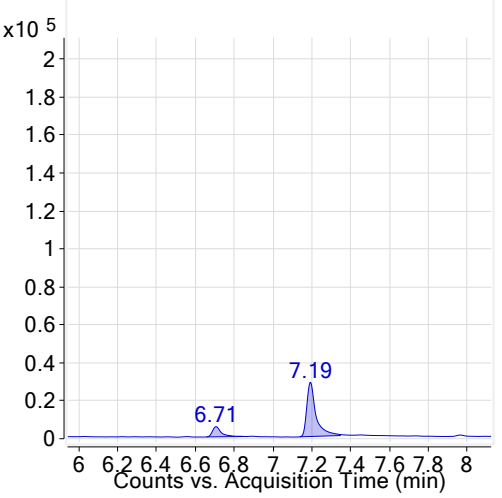

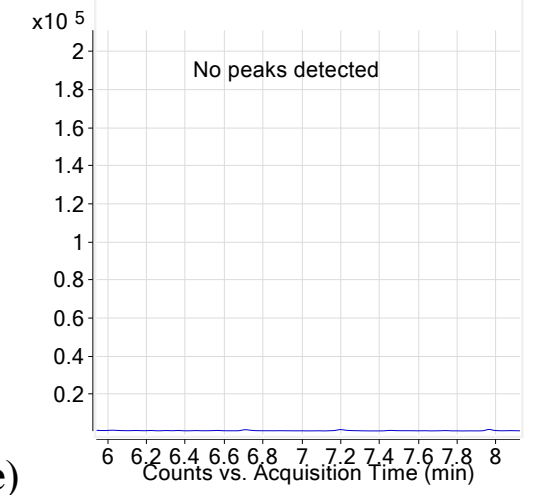

Figure S5. Chromatograms obtained from GC-MS/MS analyses of $18 \mathrm{~min}$ incubations of $124 \mathrm{mg} \mathrm{L}^{-1}$ guaiacol and $\mathrm{NaBr}$ with $300 \mathrm{mg}$ $\mathrm{L}^{-1} \mathrm{MnO}_{2}$. Panels (a), (b), and (c) correspond to 4, 40, and $160 \mathrm{mg} \mathrm{L}^{-1} \mathrm{Br}^{-}$, respectively. The products in order of peak retention time are as follows: $6.7 \mathrm{~min}$ (4-bromoguaiacol) and $7.2 \mathrm{~min}$ (6-bromoguaiacol). Panel (d) corresponds to a $500 \mu \mathrm{g} \mathrm{L}^{-1}$ standard of the two products. Panel (e) shows a $\mathrm{MnO}_{2}$-free control. No product peaks were detected in the absence of $\mathrm{MnO}_{2}$. 
a)
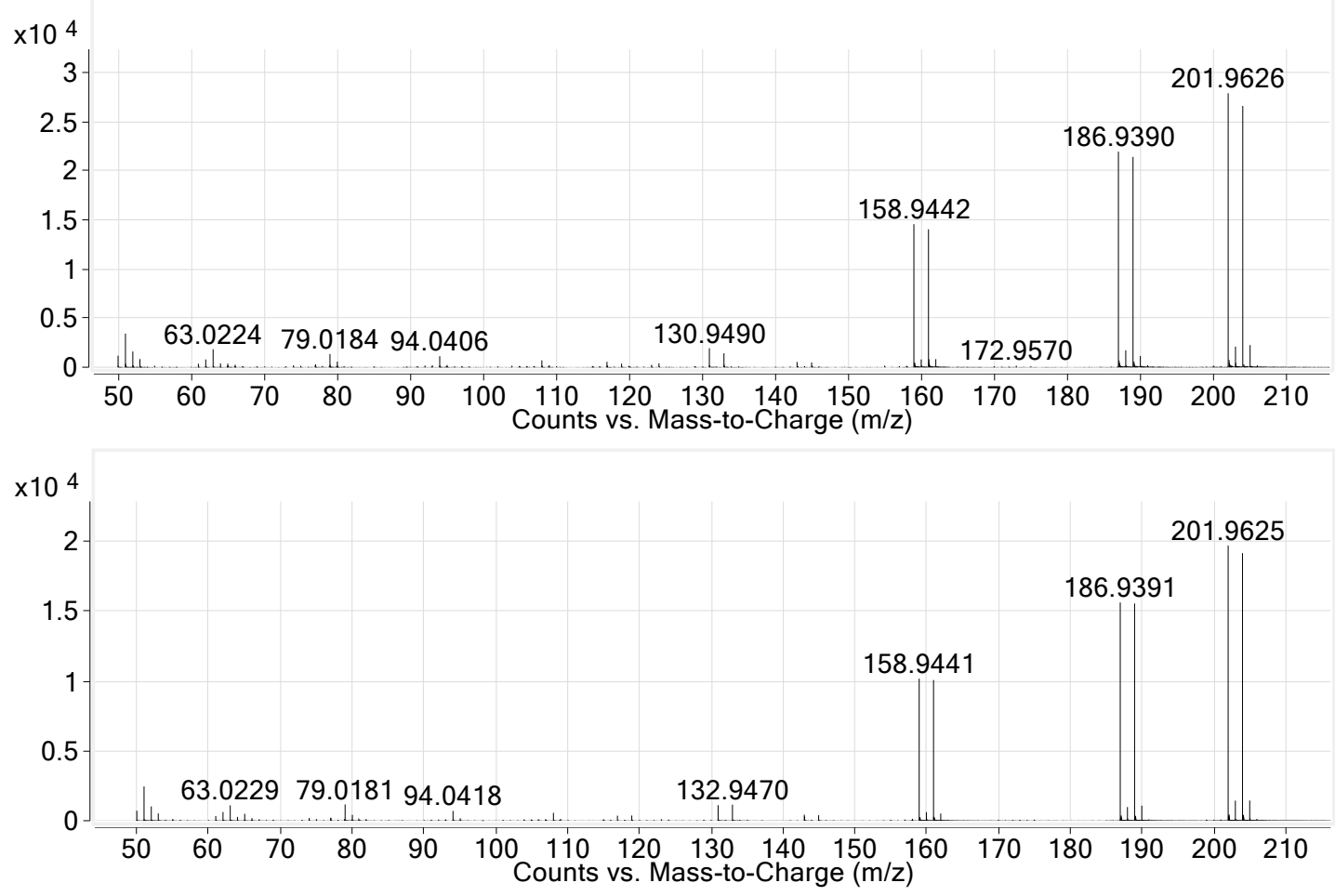

b)

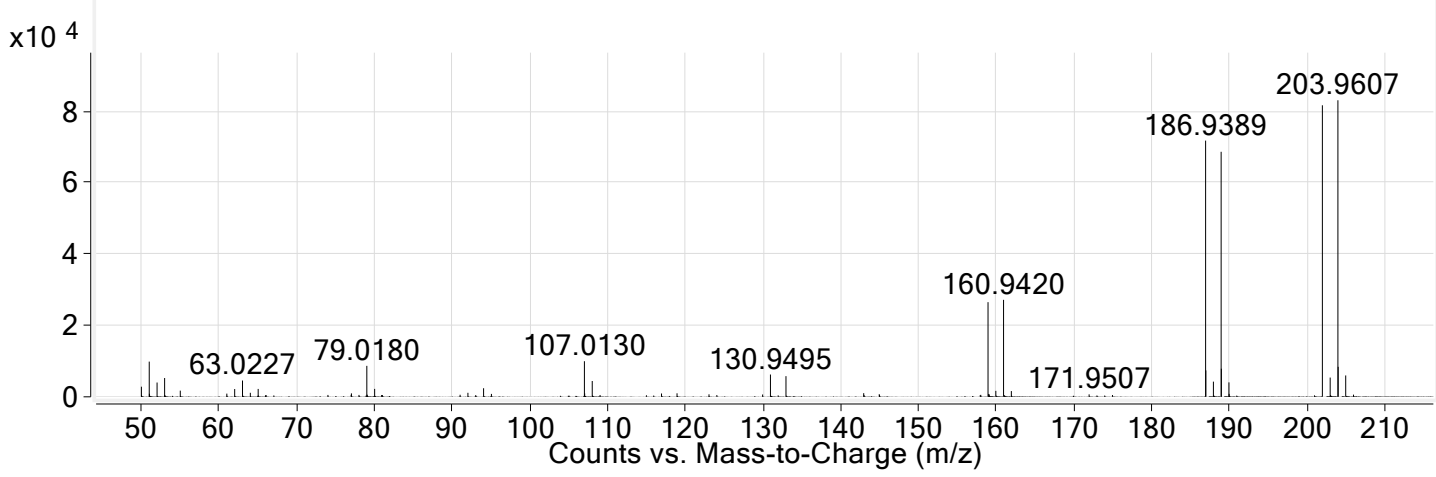

c)

$\mathrm{x} 10^{4}$

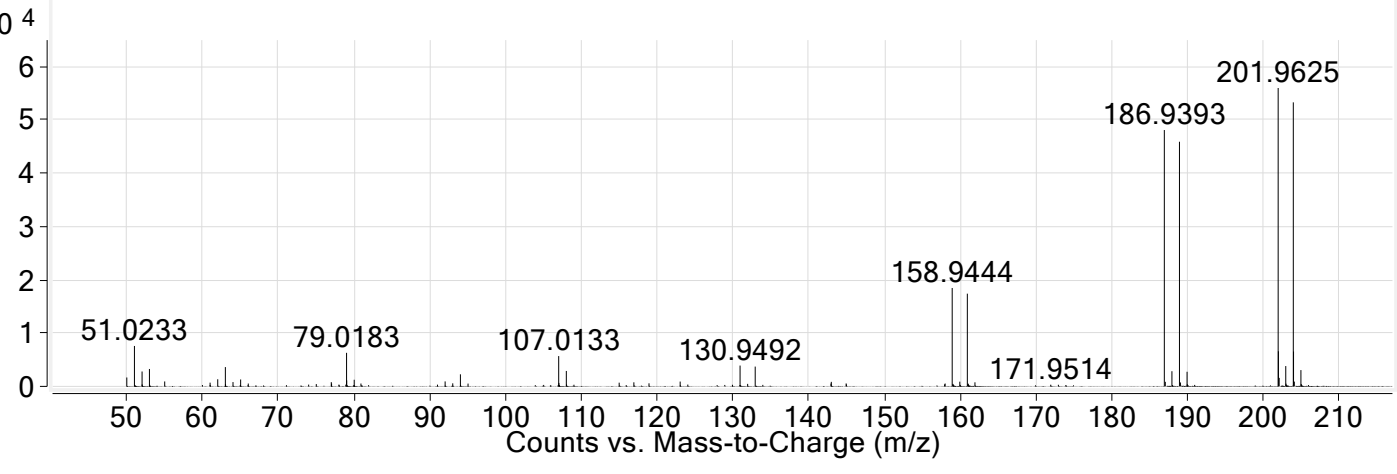

d)

Figure S6. Mass spectra obtained from GC-QToF analyses of an 18 min incubation of $300 \mathrm{mg} \mathrm{L}^{-}$ $1 \mathrm{MnO}_{2}$ with $124 \mathrm{mg} \mathrm{L}^{-1}$ guaiacol and $19,975 \mathrm{mg} \mathrm{L}^{-1} \mathrm{Br}^{-}$. Panel (a) is a spectrum of 4bromoguaiacol at $15.6 \mathrm{~min}$, with mass difference $-1.0 \mathrm{ppm}$ and NIST Match Factor 871; panel (b) is a $1 \mathrm{mg} \mathrm{L}^{-1}$ standard for 4-bromoguaiacol at $15.6 \mathrm{~min}$. Panel (c) is a spectrum of 6-bromoguaiacol at $16.1 \mathrm{~min}$, with mass difference $-1.0 \mathrm{ppm}$ and NIST Match Factor 891; panel (d) is a $1 \mathrm{mg} \mathrm{L}^{-1}$ standard for 6-bromoguaiacol at $16.1 \mathrm{~min}$. 


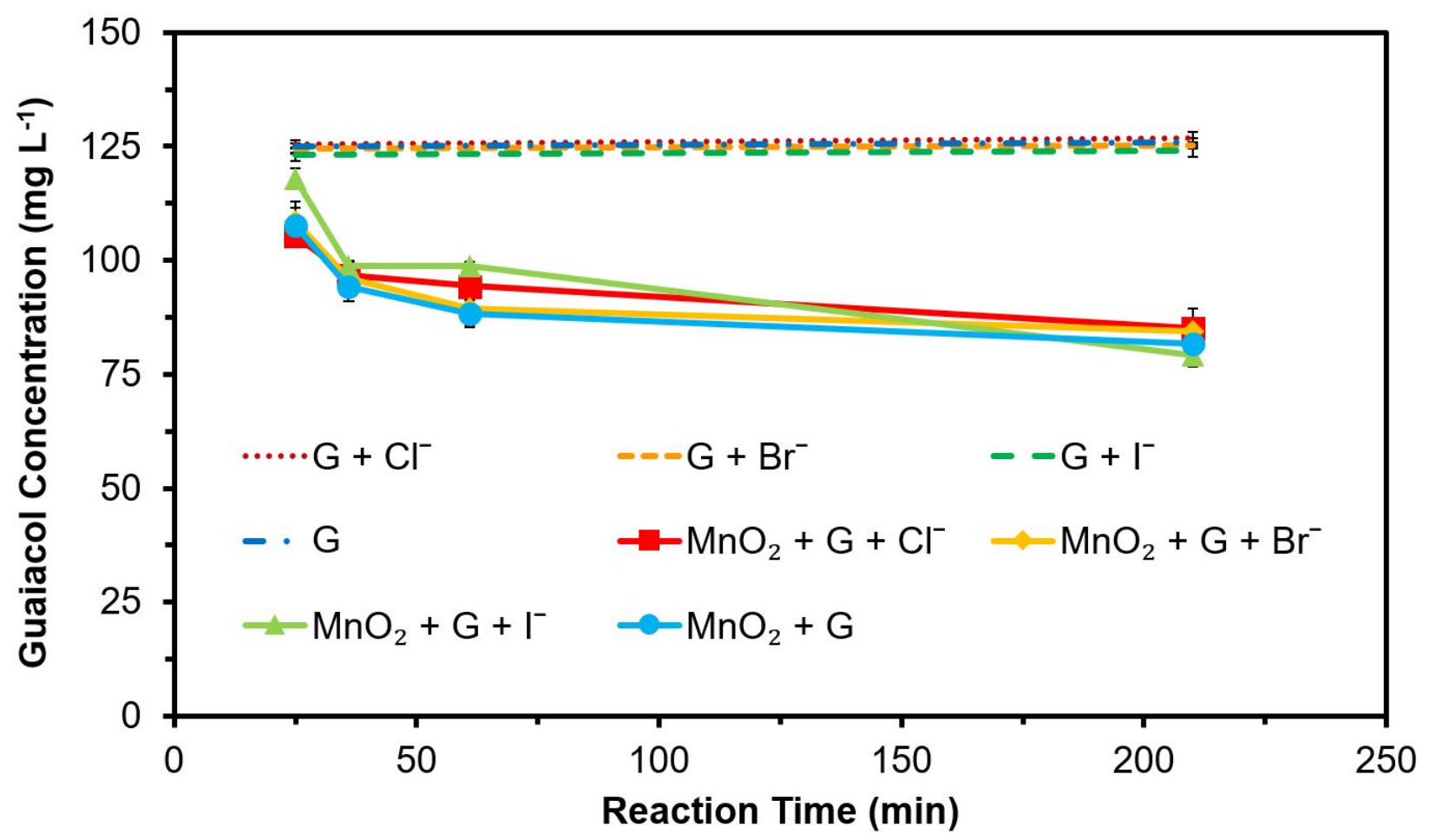

Figure S7. Guaiacol concentration over time in incubations with halides and $\mathrm{MnO}_{2}$. Mixtures contained $124 \mathrm{mg} \mathrm{L}^{-1}$ guaiacol (G), $354 \mathrm{mg} \mathrm{L}^{-1} \mathrm{Cl}^{-}, 799 \mathrm{mg} \mathrm{L}^{-1} \mathrm{Br}^{-}, 1,269 \mathrm{mg} \mathrm{L}^{-1} \mathrm{I}^{-}$, and/or $300 \mathrm{mg}$ $\mathrm{L}^{-1} \mathrm{MnO}_{2}$. The error bars represent the standard deviation $(\mathrm{n}=3)$. 


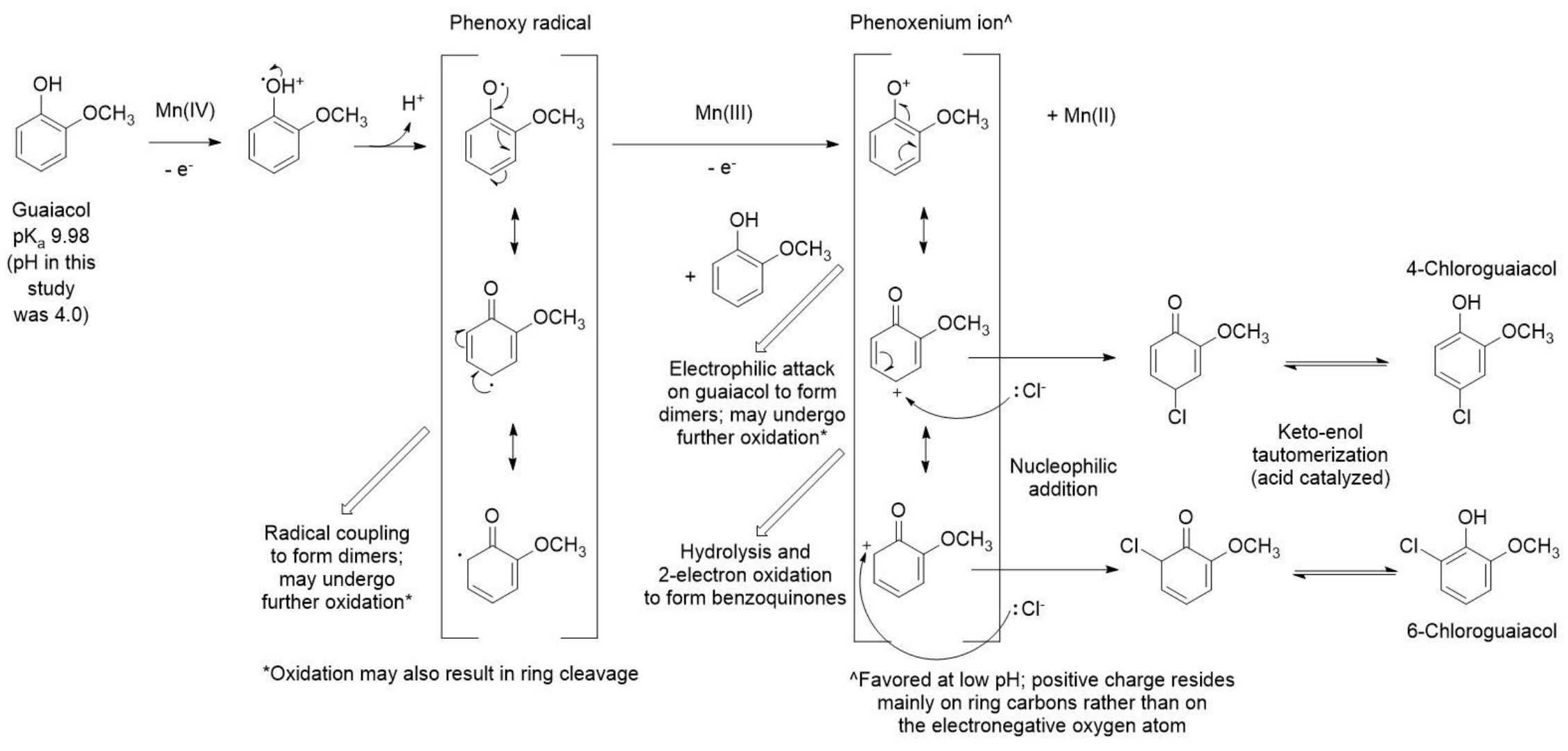

Figure S8. Proposed mechanism for $\mathrm{MnO}_{2}$-mediated chlorination of guaiacol. A similar mechanism is proposed for $\mathrm{MnO}_{2}-\mathrm{mediated}$ bromination of guaiacol. Guaiacol is first oxidized by $\mathrm{MnO}_{2}$ to a phenoxy radical, which can take on different resonance structures ${ }^{2,3}$. Phenoxy radicals can couple to form dimers and oligomers, which were observed in this study ${ }^{2,4-7}$. The phenoxy radical may also be further oxidized (e.g., by $\mathrm{Mn}(\mathrm{III})$ ) to a phenoxenium ion ${ }^{2,6}$. The electronegative, electron-deficient oxygen atom of the phenoxenium ion pulls electrons from the ring such that the positive charge exists primarily as a ring carbocation (i.e., ortho or para to this oxygen atom $)^{3,8}$. The phenoxenium ion can electrophilically attack guaiacol to form dimers, or it can undergo hydrolysis and further oxidation to form benzoquinones ${ }^{2,4,6}$. A nucleophile, like chloride or bromide, may also attack the phenoxenium ion at the carbocation, ultimately forming the products observed in this study after tautomerization ${ }^{8}$. 6-Chloroguaiacol and 6-bromoguaiacol form when the nucleophilic addition is at the ortho position; 4-chloroguaiacol and 4-bromoguaiacol form when the nucleophilic addition is at the para position. 


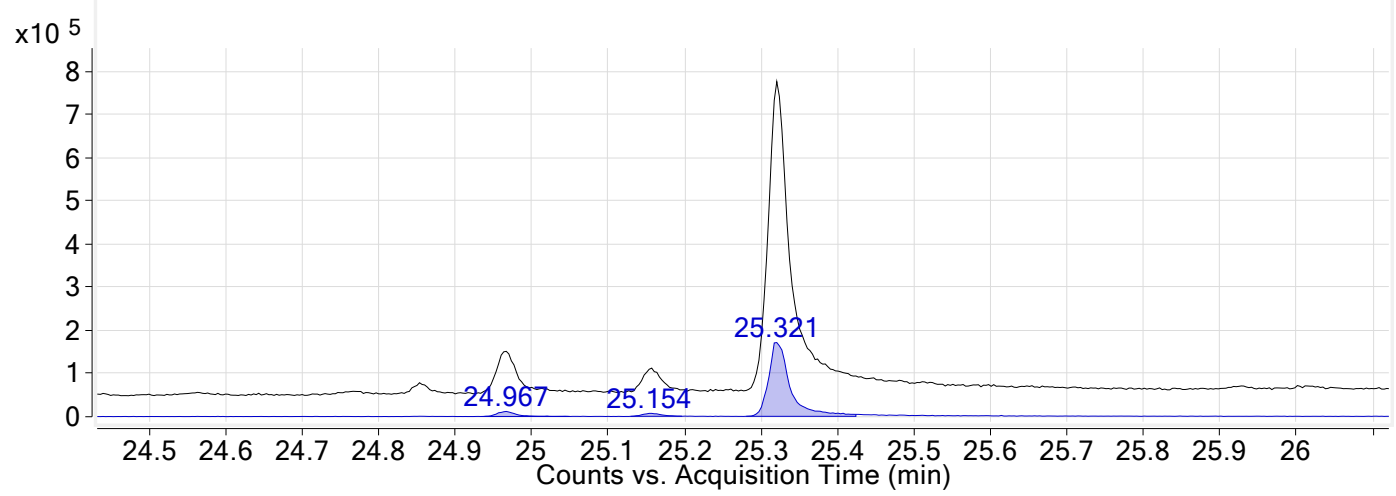

a)

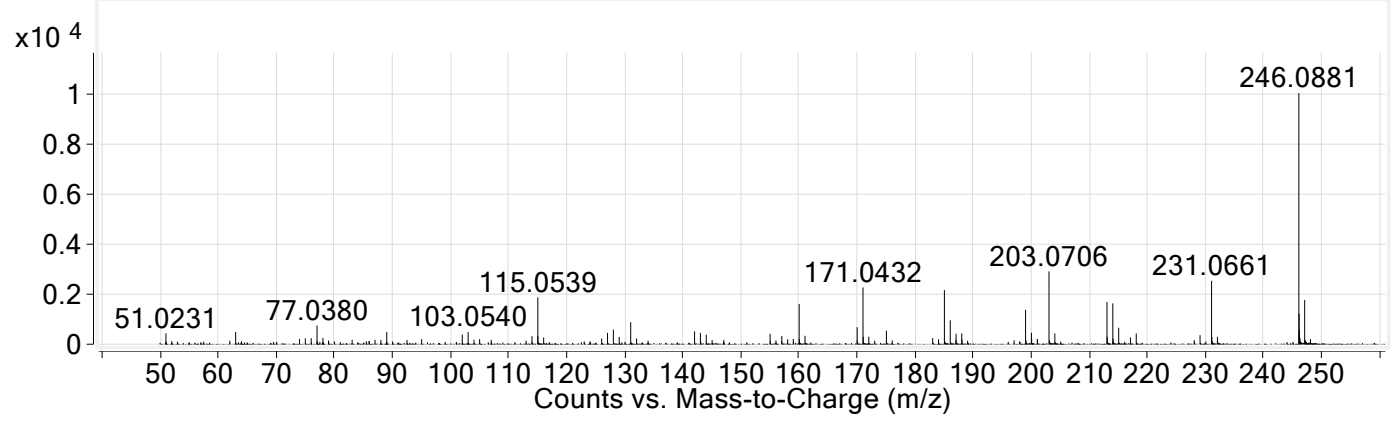

b)

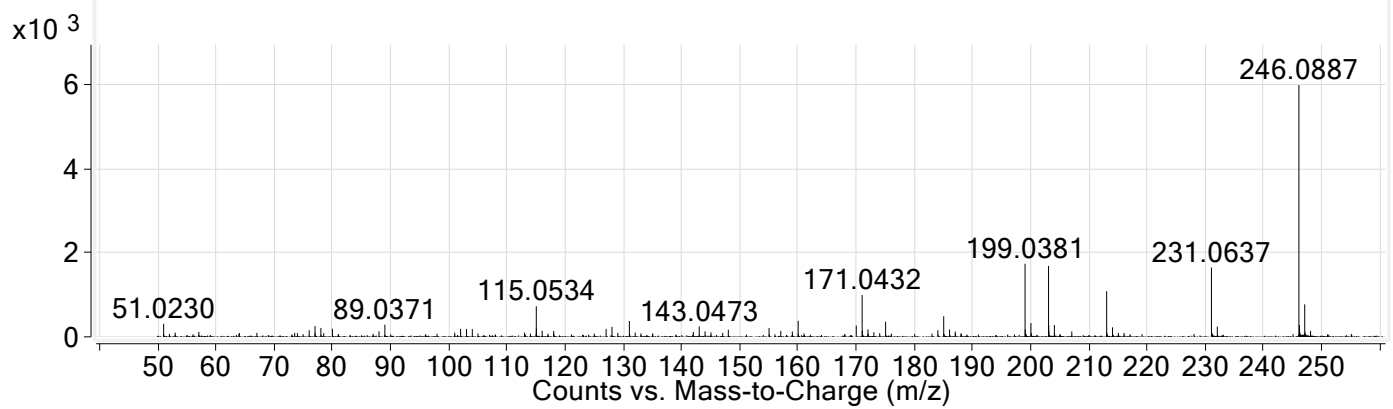

c)

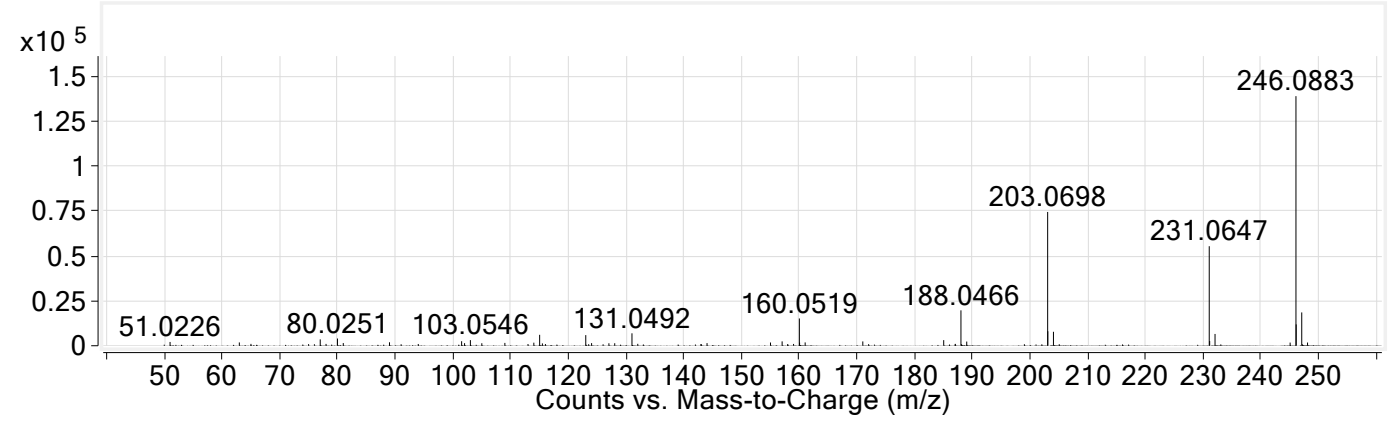

Figure S9. Mass spectral evidence of the formation of guaiacol dimers obtained from GC-QToF analyses of an $18 \mathrm{~min}$ incubation of $300 \mathrm{mg} \mathrm{L}^{-1} \mathrm{MnO}_{2}$ with $124 \mathrm{mg} \mathrm{L}^{-1}$ guaiacol and 8,862 $\mathrm{mg} \mathrm{L}^{-}$ ${ }^{1} \mathrm{Cl}^{-}$. Panel (a) is a chromatogram showing three dimer peaks. Panel (b) is a mass spectrum of the dimer eluting at $25.0 \mathrm{~min}$, with mass difference $2.3 \mathrm{ppm}$ for the molecular ion and NIST Match Factor 598; panel (c) is a mass spectrum of the dimer eluting at $25.2 \mathrm{~min}$, with mass difference 0.2 ppm for the molecular ion and NIST Match Factor 549; panel (d) is a mass spectrum of the dimer eluting at $25.3 \mathrm{~min}$, with mass difference $1.5 \mathrm{ppm}$ for the molecular ion and NIST Match Factor 878 . 


\section{References}

1 Bard, A. J. P., R.; Jordan, J. Standard Potentials in Aqueous Solution. (Routledge, 2017).

2 Remucal, C. K. \& Ginder-Vogel, M. A critical review of the reactivity of manganese oxides with organic contaminants. . Environmental Science-Processes \& Impacts 16, 1247-1266 (2014).

3 Quideau, S., Deffieux, D. \& Pouységu, L. in Comprehensive Organic Synthesis (Second Edition) (ed Paul Knochel) 656-740 (Elsevier, 2014).

4 Stone, A. T. Reductive Dissolution of Manganese(III/Iv) Oxides by Substituted Phenols. Environ Sci Technol 21, 979-988, doi:10.1021/es50001a011 (1987).

5 Simmons, K. E., Minard, R. D. \& Bollag, J. M. Oxidative coupling and polymerization of guaiacol, a lignin derivative. Soil Science Society of America Journal 52, 1356-1360, doi:10.2136/sssaj1988.03615995005200050028x (1988).

6 Hwang, S., Lee, C.-H. \& Ahn, I.-S. Product identification of guaiacol oxidation catalyzed by manganese peroxidase. Journal of Industrial and Engineering Chemistry 14, 487-492, doi:https://doi.org/10.1016/j.jiec.2008.02.008 (2008).

7 Li, C. L., Zhang, B., Ertunc, T., Schaeffer, A. \& Ji, R. Birnessite-Induced Binding of Phenolic Monomers to Soil Humic Substances and Nature of the Bound Residues. Environmental Science \& Technology 46, 8843-8850, doi:10.1021/es3018732 (2012).

8 Endo, Y. \& Shudo, K. [Phenoxenium ions: generations and reactions]. Yakugaku Zasshi 114, 565-576, doi:10.1248/yakushi1947.114.8_565(1994). 